\title{
Classifying previously undefined days from eleven years of aerosol-particle-size distribution data from the SMEAR II station, Hyytiälä, Finland
}

\author{
S. Buenrostro Mazon ${ }^{1}$, I. Riipinen ${ }^{1}$, D. M. Schultz ${ }^{1,2}$, M. Valtanen ${ }^{3}$, M. Dal Maso ${ }^{1,4}$, L. Sogacheva ${ }^{1}$, H. Junninen ${ }^{1}$, \\ T. Nieminen ${ }^{1}$, V.-M. Kerminen ${ }^{2}$, and M. Kulmala ${ }^{1}$ \\ ${ }^{1}$ Department of Physics, University of Helsinki, Finland \\ ${ }^{2}$ Finnish Meteorological Institute, Helsinki, Finland \\ ${ }^{3}$ Department of Environmental Science, University of Kuopio, Finland \\ ${ }^{4}$ Institut für Chemie und Dynamik der Geosphäre, Forschungszentrum Jülich, Germany
}

Received: 27 May 2008 - Published in Atmos. Chem. Phys. Discuss.: 4 July 2008

Revised: 25 November 2008 - Accepted: 16 December 2008 - Published: 28 January 2009

\begin{abstract}
Studies of secondary aerosol-particle formation depend on identifying days in which new particle formation occurs and, by comparing them to days with no signs of particle formation, identifying the conditions favourable for formation. Continuous aerosol size distribution data has been collected at the SMEAR II station in a boreal forest in Hyytiälä, Finland, since 1996, making it the longest time series of aerosol size distributions available worldwide. In previous studies, the data have been classified as particleformation event, nonevent, and undefined days, with almost $40 \%$ of the dataset classified as undefined. In the present study, eleven years (1996-2006) of undefined days (1630 days) were reanalyzed and subdivided into three new classes: failed events (37\% of all previously undefined days), ultrafine-mode concentration peaks (34\%), and pollutionrelated concentration peaks (19\%). Unclassified days (10\%) comprised the rest of the previously undefined days. The failed events were further subdivided into tail events $(21 \%)$, where a tail of a formation event presumed to be advected to Hyytiälä from elsewhere, and quasi events (16\%) where new particles appeared at sizes 3-10 nm, but showed unclear growth, the mode persisted for less than an hour, or both. The ultrafine concentration peaks days were further subdivided into nucleation-mode peaks (24\%) and Aitken-mode peaks $(10 \%)$, depending on the size range where the particles occurred. The mean annual distribution of the failed events has a maximum during summer, whereas the two peak classes
\end{abstract}

Correspondence to: I. Riipinen (ilona.riipinen@helsinki.fi) have maxima during winter. The summer minimum previously found in the seasonal distribution of event days partially offsets a summer maximum in failed-event days. Dailymean relative humidity and condensation sink values are useful in discriminating the new classes from each other. Specifically, event days had low values of relative humidity and condensation sink relative to nonevent days. Failed-event days possessed intermediate condensation sink and relative humidity values, whereas both ultrafine-mode peaks and, to a greater extent, pollution-related peaks had high values of both, similar to nonevent days. Using 96-h back trajectories, particle-size concentrations were plotted as a function of time the trajectory spent over land. Increases in particle size and number concentration during failed-event days were similar to that during the later stages of event days, whereas the particle size and number concentration for both nonevent and peaks classes did not increase as fast as for event and failed events days.

\section{Introduction}

The formation and growth of new secondary aerosol particles has been observed around the world (Kulmala et al., 2004a) and has a significant impact on the global aerosol loading (Spracklen et al., 2006). The climatic importance of newly formed aerosols as potential cloud condensation nuclei (e.g. Lohmann and Feichter, 2005) propels the scientific community to understand the mechanisms that increase their concentration in the atmosphere. 
Continuous datasets of aerosol-particle-size distributions are useful to study the long-term behaviour of the particle source caused by secondary aerosol formation. So far, the longest such dataset has been recorded at the SMEAR II station located in a boreal forest, Hyytiälä, Finland (Hari and Kulmala, 2005), where continuous size distributions have been measured since 1996. The secondary particle formation episodes, hereafter referred to as event days, and the days without indications of particle formation, or nonevent days, have been selected from the dataset by classifying all the measured particle-size spectra according to the criteria devised by Dal Maso et al. (2005, 2007). This classification was designed to make a clean separation between event and nonevent days and to find the most important factors influencing whether particles form or not. However, particleformation events clearly have some thresholds for appearance - they are not simply an on/off phenomenon. Specifically, deciding whether particle formation occurred or not may be ambiguous. To reveal the formation mechanisms more clearly, clear event days and clear nonevent days were identified, leaving the remaining data to be classified as undefined days (Dal Maso et al., 2005, 2007). However, the ultimate aim of scientists investigating particle formation is not only to describe the formation mechanism qualitatively, but to estimate the influence of particle formation on the atmosphere quantitatively. In other words, how many particles are created during particle-formation events, how is this number influenced by other particles present, and what factors promote or inhibit new-particle formation and growth?

Although almost a third of the days have been labelled as event days, approximately $40 \%$ of the data is classified as undefined: neither event nor nonevent days. By not considering undefined days, we risk making a quantitative error. Do particles form on some undefined days? If so, how often? Do such days produce the same number of particles? If not, why? Furthermore, does a comparison of undefined days to event and nonevent days tell us more specifics about the characteristics of days when particle formation occurs?

To find answers to these questions, we give a renewed look to those days that were previously classified as undefined. Eleven years (1996-2006) of particle-size-distribution data was analyzed. Our analysis shows that distinct categories could be identified among the undefined days, leading to a new classification scheme that further subdivides the undefined days. The new classification scheme includes three categories based on the different physical characteristics of the particle number size distribution.

The rest of the article is as follows. The data and the new classification scheme are described in Sect. 2. Section 3 presents the frequency of occurrence of these classification schemes over the 11-year period and the mean annual cycle. Section 4 presents a discussion, further analyzing the differences between the classes. Finally, Sect. 5 summarizes this article.

\section{Methods}

\subsection{Site description and instrumentation}

The measurement station SMEAR II (System for Measuring Forest Ecosystem-Atmosphere Relationships II, Hari and Kulmala, 2005) is one of three University of Helsinki stations dedicated to the investigation of the atmosphere-biosphere system. The field station is located in a Scots pine forest in Hyytiälä, Finland $\left(61^{\circ} 51^{\prime} \mathrm{N}, 24^{\circ} 17^{\prime} \mathrm{E}\right), 60 \mathrm{~km}$ northeast of the nearest city, Tampere, and $200 \mathrm{~km}$ northwest of Helsinki. The SMEAR II station measures atmospheric gas concentrations, radiation, and meteorological variables. A 73-m mast records continuous gas concentrations of $\mathrm{NO}_{\mathrm{x}}, \mathrm{CO}_{2}, \mathrm{CO}$, $\mathrm{SO}_{2}, \mathrm{O}_{3}$, and $\mathrm{H}_{2} \mathrm{O}$ at six different height levels (Kulmala et al., 2001). The gas concentrations used in this study are measured at a height of $67.2 \mathrm{~m}$.

The aerosol-particle-size distributions are measured with a pair of Differential Mobility Particle Sizer (DMPS) systems (Mäkelä et al., 2000; Aalto et al., 2003), consisting of a Differential Mobility Analyser (DMA) to size-classify the sampled aerosol particles, followed by a Condensation Particle Counter (CPC) to count the number of particles in each size bin. The DMPS systems measure at a lower- $(3-10 \mathrm{~nm})$ and upper-size range $(10-500 \mathrm{~nm})$ every $10 \mathrm{~min}$.

\subsection{Classification of undefined days}

The classification scheme devised by Dal Maso et al. (2005) has been used to classify 11 years of particle size distribution data from the SMEAR II station to identify and separate newparticle-formation event days from nonevent days as reliably as possible. The established classification scheme labels a day as a particle-formation event, a nonevent, or, if ambiguous, undefined. The classification scheme by Dal Maso et al. (2005) was based on analyzing daily DMPS plots and visually deciding if a day is a new-particle-formation event. The criteria for a new-particle-formation event were a distinct new mode appearing within the nucleation-mode size range ( $<25 \mathrm{~nm}$ ), persisting for more than an hour, and growing to larger sizes within several hours. A nonevent typically showed particle concentrations at sizes larger than nucleation mode and lacked the appearance of a distinguishable new mode (i.e. particle formation). A day that clearly showed an increase in concentration in the nucleation mode but occurred in bursts throughout the day, showed no growth, or whose activity began near or at Aitken-mode size range, remained inconclusive and was binned in an undefined class. Previous research has focused on comparing event with nonevent days, but the abundance of undefined days in the dataset (40\%) encouraged this study. To better understand the processes acting on undefined days, this study aims to classify them. This classification was performed using manual analysis of DMPS plots and $\mathrm{NO}_{\mathrm{x}}$ and $\mathrm{SO}_{2}$ concentrations. 
Table 1. The new classification scheme for previously undefined days. The characteristics are determined through visual inspections of DMPS plots and time series of particle-number, $\mathrm{SO}_{2}$, and $\mathrm{NO}_{\mathrm{x}}$ concentrations.

\begin{tabular}{|c|c|}
\hline Class & Characteristics \\
\hline \multicolumn{2}{|l|}{ 1. Failed events } \\
\hline a. Quasi events & $\begin{array}{l}\text { A new nucleation mode at geometric particle diameters } D_{p} 3-10 \mathrm{~nm} \text {, but the mode fails to } \\
\text { achieve clear growth, the mode lasts for less than one hour, or both. }\end{array}$ \\
\hline b. Tail events & A new mode appears at particle diameters greater than $10 \mathrm{~nm}$ and grows for several hours. \\
\hline 2. Pollution-related concentration peaks & $\begin{array}{l}\text { Peaks in particle concentration coinciding with elevated concentrations of } \\
\mathrm{SO}_{2}(>1 \mathrm{ppb}) \text { or } \mathrm{NO}_{\mathrm{x}}(>5 \mathrm{ppb})\end{array}$ \\
\hline \multicolumn{2}{|l|}{ 3. Ultrafine-mode peaks } \\
\hline a. Aitken-mode peaks & $\begin{array}{l}\text { Particles appear at sizes between } 10 \text { and } 100 \mathrm{~nm} \text {, but does not grow. Low concentrations } \\
\text { of } \mathrm{SO}_{2}(<1 \mathrm{ppb}) \text { and } \mathrm{NO}_{\mathrm{x}}(<5 \mathrm{ppb}) \text {. }\end{array}$ \\
\hline b. Nucleation-mode peaks & $\begin{array}{l}\text { Particles appear at sizes between } 3 \text { and } 30 \mathrm{~nm} \text {, but does not grow. } \\
\text { Low concentrations of } \mathrm{SO}_{2}(<1 \mathrm{ppb}) \text { and } \mathrm{NO}_{\mathrm{x}}(<5 \mathrm{ppb}) \text {. }\end{array}$ \\
\hline 4. Unclassified & Not suitable for any of the above classes. \\
\hline 5. Missing Data & DMPS data missing partly or completely. \\
\hline
\end{tabular}

To create an initial classification scheme for testing, the year 2004, arbitrarily selected, was studied by collecting and comparing examples of DMPS plots from event, nonevent, and undefined days. The aim was to identify the similarity between undefined days and event days that had caused the ambiguity and prevented them from being classified as nonevents; in the same way, we looked for traits in the undefined days that were missing in nonevent days. Previous observations (e.g. Mäkela et al., 2000; Dal Maso et al., 2005) detected growth in the Aitken-mode size range during the evenings, as well as sporadic fluctuations in size concentration within the nucleation mode, which make the days difficult to classify. These observations were considered when constructing the classification scheme presented here. Based on the analysis of the 2004 data, five classes were created to subdivide the previously undefined days, and this classification scheme was subsequently applied to all 11 years of data (Table 1). The data were initially classified by one person and further validated by a panel of three researchers, different from those that created the scheme.

\subsubsection{Class 1: Failed particle formation event days}

The first class includes the undefined days that closely resemble, in part, an event day as described by Dal Maso et al. (2005). This class was termed failed events, for reasons that will be developed throughout the rest of this article. Two subdivisions of the failed events were identified: quasi events and tail events. Figure 1 shows two examples of failed-event days.

Quasi events are days that meet the criteria for new particle formation with a new nucleation mode at geometric particle diameters $\left(D_{p}\right) 3-10 \mathrm{~nm}$, but the mode fails to achieve clear growth, the mode lasts for less than one hour, or both.
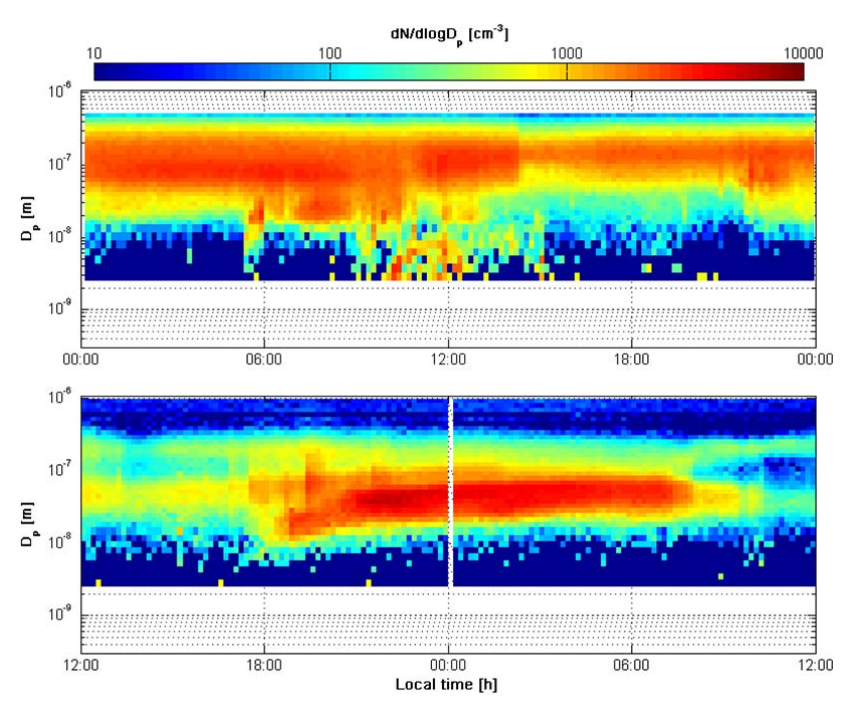

Fig. 1. Examples of failed events at the SMEAR II station, Hyytiälä, Finland: Upper panel: Quasi event (1 May 2004); lower panel: Tail event (12:00 Local Time 14 October 2006 to 12:00 Local Time 15 October 2006).

Tail events are days where the later half of a presumably newly formed, growing nucleation mode or the late-evening growth of new particles are observed at Hyytiälä, suggesting that the new particles formed elsewhere and were advected to Hyytiälä. The classification criteria for a tail event are that a new mode appears at particle diameters greater than $10 \mathrm{~nm}$ and grows for several hours.

\subsubsection{Class 2: Pollution-related concentration peaks}

The days with pollution-related concentration peaks feature an increase in particle concentration at any size range, herein 


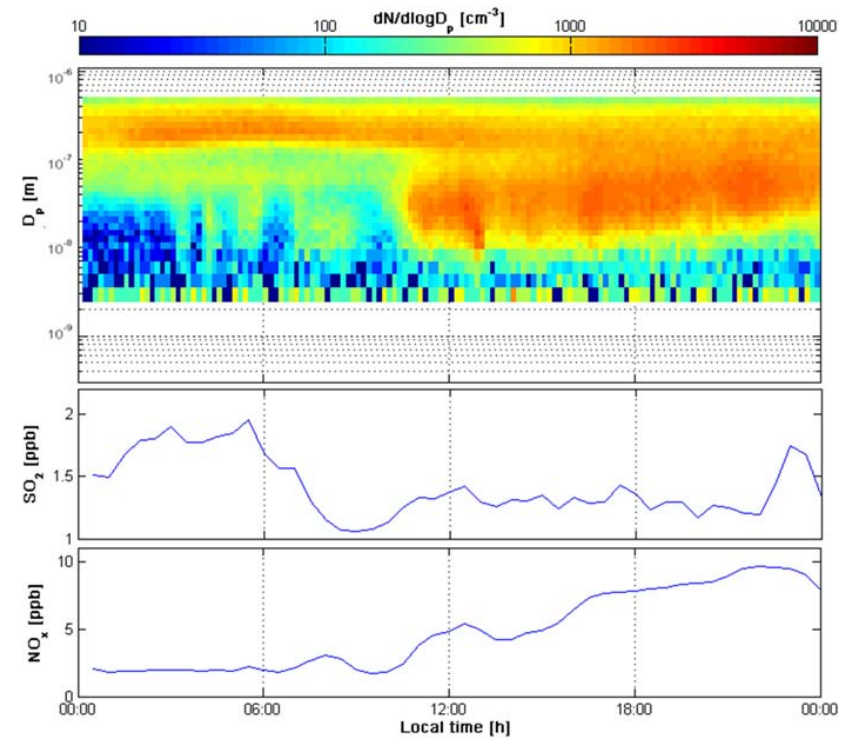

Fig. 2. Undefined day reclassified as pollution-related concentration peaks (14 December 1998) at the SMEAR II station, Hyytiälä, Finland. (a) DMPS data, (b) $\mathrm{SO}_{2}$ concentration (ppb), and (c) $\mathrm{NO}_{\mathrm{x}}$ concentration (ppb). After 12:00 Local Time, $\mathrm{NO}_{\mathrm{x}}$ concentration increases at the same time that a mode in the Aitken size appears.

referred to as a peak in the DMPS plot, coincident in time with either elevated $\mathrm{SO}_{2}$ or $\mathrm{NO}_{\mathrm{x}}$ concentrations greater than or equal to $1 \dot{\mathrm{p} p b}$ and $5 \mathrm{ppb}$, respectively. These concentration thresholds were loosely defined after noting that continental air masses usually surpass these values. The median concentrations of $\mathrm{SO}_{2}$ and $\mathrm{NO}_{\mathrm{x}}$ during the dataset are 0.2 and $1.4 \mathrm{ppb}$, respectively. Figure 2 shows an example of a pollution-related concentration peak day.

\subsubsection{Class 3: Ultrafine-mode concentration peaks}

The ultrafine-mode concentration peaks class includes the days with peaks, but without growth, in the nucleation-mode size range or Aitken-mode size range, respectively termed nucleation-mode peaks and Aitken-mode peaks. The peaks coincide in time with low $\mathrm{SO}_{2}$ and $\mathrm{NO}_{\mathrm{x}}$ concentrations, separating this class from the pollution-related concentration peaks class. Figure 3 shows an example of an ultrafine-mode concentration peak day.

\subsubsection{Unclassified and missing data}

If a day does not fit one of the previous three class descriptions, it is termed unclassified. Doswell (1991) argued that classification schemes should have an unclassifiable category to avoid shoehorning unusual events into arbitrary categories.

A day is labelled as missing data when the DMPS data is incomplete or missing altogether. In the case where data from just the morning or night are missing, but a clearly classifiable characteristic starts at the available DMPS plot, the

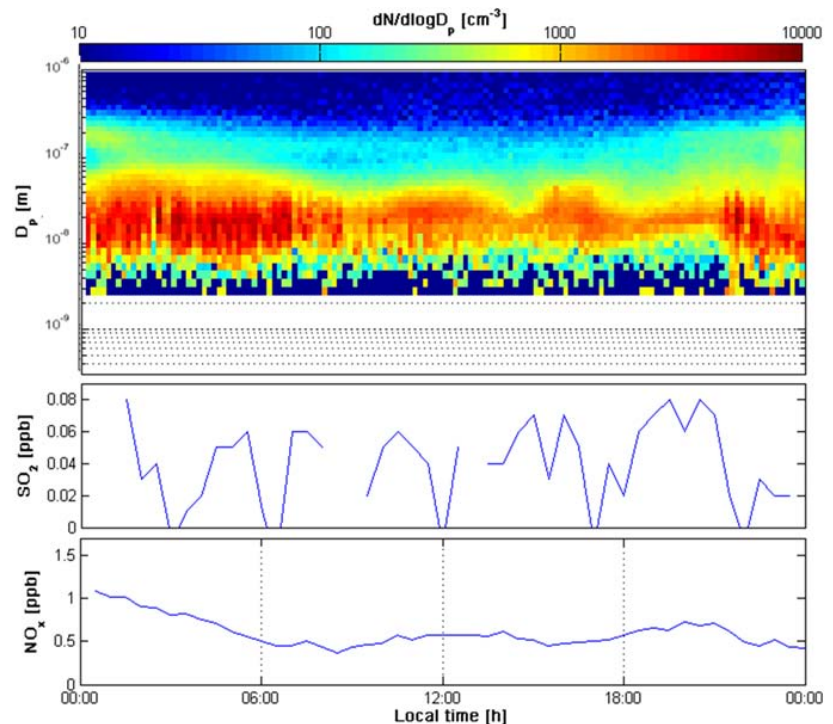

Fig. 3. Undefined day reclassified as nucleation mode peaks (31 December 2004) at the SMEAR II station, Hyytiälä, Finland. (a) DMPS data, (b) $\mathrm{SO}_{2}$ concentration (ppb), and (c) $\mathrm{NO}_{\mathrm{x}}$ concentration (ppb). No apparent relationship exists between the gas concentrations and the noisy nucleation-mode particle concentrations in the DMPS data during the morning (before 09:00 Local Time) and night (after 21:00 Local Time).

day is classified and not discarded as missing data. When the data indicate a day potentially classifiable either as a pollution-related concentration peak or ultrafine-mode concentration peak day, but no gas concentration data is available, the day is labelled unclassified.

\subsubsection{Classifying the data}

The data were analyzed using multiple-days views, where two full consecutive days were plotted together as a 48-h time series, allowing for recognition of possible night formation events. The transition from one day to another was analyzed for every day. Based on the classification devised for the undefined days and the established classification of events, each day was accordingly classified as an event, nonevent, failed event (quasi or tail), pollution-related peaks, ultrafinemode peaks (nucleation- and Aitken-mode), unclassified, or missing data. Figure 4 shows the flowchart for classification, which is revised from the one presented by Dal Maso et al. (2005) to include the new subdivisions of the previously undefined days. This new classification of the days was compared to how they were previously classified according to Dal Maso et al. (2005, 2007). For nearly all of the days, the new classification agreed with their previous classification as events, nonevents, or undefined. 
Table 2. Statistics for the new classification scheme for previously undefined days for 1996-2006 from the SMEAR II station, Hyytiälä, Finland.

\begin{tabular}{|c|c|c|c|c|c|c|c|c|c|c|c|c|}
\hline Year & 1996 & 1997 & 1998 & 1999 & 2000 & 2001 & 2002 & 2003 & 2004 & 2005 & 2006 & Total \\
\hline Total undefined & 177 & 178 & 174 & 183 & 151 & 158 & 181 & 159 & 172 & 158 & 170 & 1861 \\
\hline 1. Failed events & 32 & 48 & 52 & 52 & 49 & 55 & 73 & 52 & 69 & 61 & 54 & 597 \\
\hline a. Tail events & 21 & 33 & 33 & 22 & 25 & 37 & 44 & 21 & 39 & 30 & 32 & 337 \\
\hline b. Quasi events & 11 & 15 & 19 & 30 & 24 & 18 & 29 & 31 & 30 & 31 & 22 & 260 \\
\hline 2. Pollution-related peaks & 31 & 22 & 43 & 32 & 25 & 30 & 23 & 25 & 21 & 22 & 36 & 310 \\
\hline 3. Ultrafine-mode peaks & 4 & 53 & 60 & 59 & 48 & 51 & 55 & 60 & 63 & 50 & 56 & 559 \\
\hline a. Nucleation-mode & 3 & 29 & 42 & 36 & 34 & 28 & 26 & 48 & 59 & 45 & 46 & 396 \\
\hline b. Aitken-mode & 1 & 24 & 18 & 23 & 14 & 23 & 29 & 12 & 4 & 4 & 10 & 163 \\
\hline 4. Unclassified & 41 & 14 & 5 & 6 & 11 & 15 & 22 & 13 & 12 & 14 & 11 & 164 \\
\hline 5. Missing data & 69 & 41 & 14 & 34 & 18 & 7 & 8 & 9 & 7 & 11 & 13 & 231 \\
\hline
\end{tabular}

\section{Results}

\subsection{Statistics}

Table 2 summarizes the statistics for each class and its subclasses for all 11 years. The period from 31 January 1996 to 31 December 2006 had 1861 undefined days. Of these, 231 $(12 \%)$ were classified as missing data and discarded from further statistics. Of the remaining 1630 undefined days, the dominant class was the failed-event days (597 out of 1630 days, or $37 \%$ ), followed by the ultrafine-mode peaks days (559 days, or $34 \%$ ), and lastly the pollution-related peaks days (310 days, or 19\%). The failed events were further subdivided into tail events (337 days, or $21 \%$ ) and quasi events (260 days, or 16\%). The ultrafine-mode peaks days were further subdivided into nucleation-mode peaks (396 days, or $24 \%$ ) and Aitken-mode peaks (163 days, or 10\%). A total of 164 days $(10 \%)$ were placed in the unclassified category. The year 1996 had 69 days of missing data and 41 unclassified days, eliminating from further analysis more than $60 \%$ of the 177 previously undefined days that year. For this reason, monthly distributions will consist of data from 1997 to 2006.

\subsection{Interannual and seasonal distributions of the classes}

\subsubsection{Failed events}

Dal Maso et al. (2005) found that particle formation in Hyytiälä was most frequent during spring (March-May) and in September. The particle-formation event frequency exhibits a relative minimum in summer (June-August) and is lowest during the winter. In light of these findings, we compare the event days to the failed-event days. Figure 5 displays the mean annual distribution of events and failed events from the total number of classifiable days per month (i.e. excluding missing data). Around half of all undefined days between May and September each year are classified as failed events,

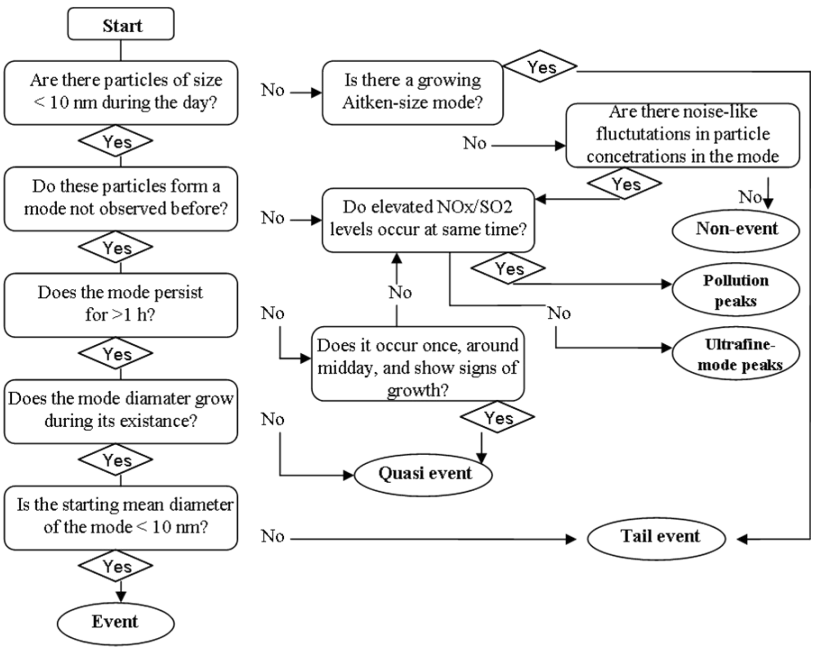

Fig. 4. Edited version of the flowchart constructed by Dal Maso et al. (2005) to classify days as events, nonevents, and undefined days with the new classes for the previously undefined days: tail events, quasi events, pollution-related peaks, and ultrafine-mode peaks.

with the bell-shaped distribution peaking in June-August. Consequently, the failed events exhibit a seasonal distribution that peaks in the summer, between, and comparable in magnitude to, the spring and fall maxima of the event days as found by Dal Maso et al. (2005). Furthermore, the sum of events and failed events lessen the summer minimum compared to the new-particle-formation event distribution. During the summer, the failed events are about a third of days, whereas spring and September days are over $30 \%$ event days. Together, the event and failed-event days dominate about half of the days during spring and summer.

The frequency of failed events is relatively consistent from year to year over the 11 years, with a slight rise during 2002 and 2004 (Fig. 6). The events, on the other hand, follow a sinusoidal cycle (Dal Maso et al., 2007), with number of events 


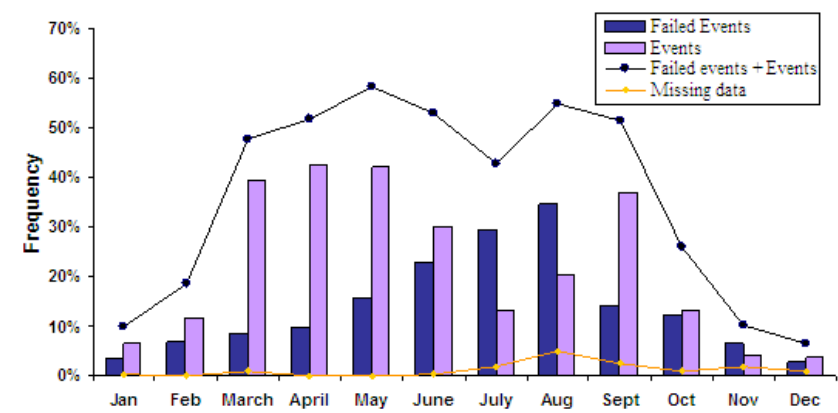

Fig. 5. Seasonal distribution of event days, failed-event days, and the sum of event and failed-event days at the SMEAR II station, Hyytiälä, Finland, during 1997-2006. Days with missing data are excluded from the total number of days per month and are plotted as a separate distribution.

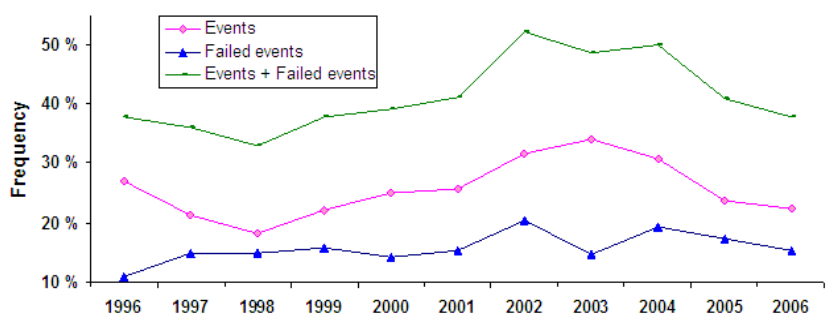

Fig. 6. Interannual variation in the frequency of failed-event days per year from 1996 to 2006 at the SMEAR II station, Hyytiälä, Finland.

peaking during 2002-2004, The mean annual percentage of failed events is $16 \%$, compared to an average $26 \%$ of event days per year.

\subsubsection{Pollution-related and ultrafine-mode concentration peaks}

The annual cycle of the frequency of days classified as pollution-related or ultrafine-mode concentration peaks is presented in Fig. 7. These classes both exhibit maxima during winter, although the ultrafine-mode peaks class features a secondary maximum during the summer that the pollutionrelated peaks class does not possess.

Lyubovtseva et al. (2005) present $\mathrm{SO}_{2}$ and $\mathrm{NO}_{\mathrm{x}}$ annual distributions for event and nonevent days, where both classes have a winter maximum and summer minimum. As expected, the pollution-related peaks class follows a similar annual distribution with elevated concentrations of $\mathrm{SO}_{2}$ and $\mathrm{NO}_{\mathrm{x}}$ (more than $1 \mathrm{ppb}$ of $\mathrm{SO}_{2}$ and $5 \mathrm{ppb}$ of $\mathrm{NO}_{\mathrm{x}}$ ). One hypothesis to explain the higher $\mathrm{SO}_{2}$ and $\mathrm{NO}_{\mathrm{x}}$ in winter is the greater emissions of these gases, as well as the more frequent occurrence of inversions in winter to increase the concentrations of these gases within the lower boundary layer.

The winter maximum in the number of ultrafine-mode peak days (Fig. 7) suggests that other locally emitted pol-

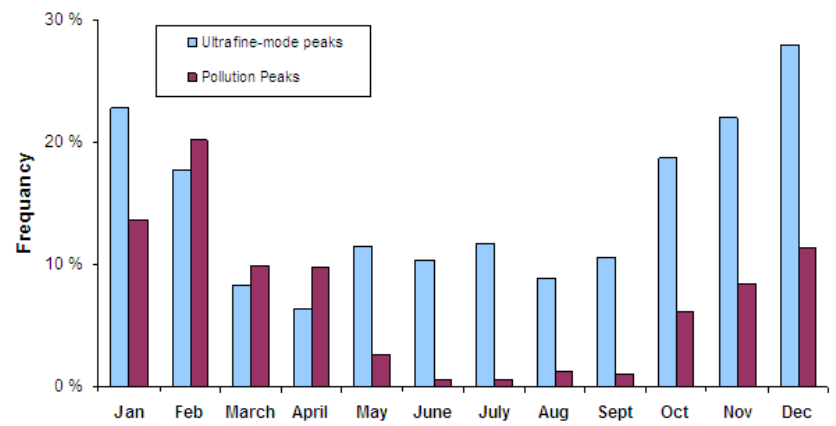

Fig. 7. Mean annual frequency of pollution-related and ultrafinemode concentration peak classes for 1997-2006 at the SMEAR II station, Hyytiälä, Finland.

luting gases or particles may be present on these days. Such gases or particles are probably of anthropogenic origin, and the increase in wood-burning in Finland could produce this winter maximum. Local traffic is also a possible source of these small particles.

A secondary maximum in the ultrafine-mode peaks class occurs in the summer (Fig. 7). The sources of ultrafine-mode peaks in the summer are more difficult to identify - such particles might be a mixture of traffic-related local pollution and small particles originating from failed events. Alternatively, this secondary maximum might not be a physical process. The slight local minimum in the spring may be offset by the maximum of event days in the spring (cf. Figs. 5 and 7), resulting in fewer days in the undefined days category and thus also fewer days classified as ultrafine-mode peaks.

Sometimes an ambiguity arises when classifying shortduration nucleation-mode peaks that might otherwise be interpreted as a quasi event. In both cases, particle concentration fluctuations in the lowest size ranges occur with no relation to elevated $\mathrm{SO}_{2}$ and $\mathrm{NO}_{\mathrm{x}}$ concentrations. This ambiguity could lead to some overlap of the quasi-event and the nucleation-mode peaks classes. However, there are some clear and ubiquitous differences between these classes: 1) on a quasi-event day the small particles typically appear and disappear around noon, thus resembling normal particle formation events; 2) the mean size of the nucleation-mode peaks is typically larger than the mode on a quasi-event day.

\section{Discussion}

The classification of days is carried out manually, by visual inspection, and determined by the judgment of the panel of researchers. Although a panel of four people was used to construct and verify the classification scheme, the scheme is - being based on a manual method - never completely free of the influence of the individuals applying it. We believe that we have produced a robust and repeatable approach, but physical trends that clearly differentiate the classes from each 

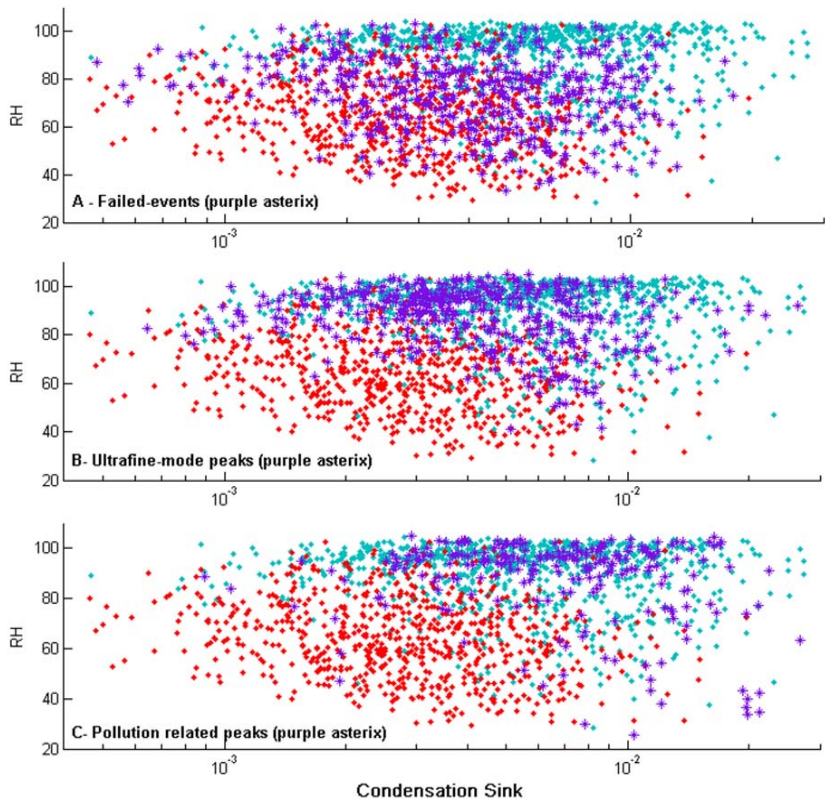

Fig. 8. Comparison of daily-mean condensation sink (CS) versus relative humidity $(\mathrm{RH})$ for the new classes (purple asterisk) relative to event (red dot) and nonevent (blue cross) days of 1996-2006 in Hyytiälä, Finland. ((a): failed events; (b): ultrafine-mode peaks; (c): pollutionconcentration related peaks).

other help to validate our scheme. For example, the mean monthly frequencies of the classes shows a clear annual cycle with the failed events most frequent in summer (Fig. 5) and the peaks classes most frequent in winter (Fig. 7). Additional physical reasoning in the previous section provides justification for these annual cycles, further validating our approach. In this section, we further explore the physical differences between the different classes.

Hyvönen et al. (2005) tested numerous meteorological variables, gas concentrations, and aerosol parameters to predict aerosol-particle formation. Their data mining concluded that relative humidity $(\mathrm{RH})$ and condensation sink (CS) were the best pair of indicators for new particle formation event. Low values of CS and RH hinder coagulation and lower the scavenging of small particles and condensable vapours, and thus promote particle formation. In contrast, nonevent days tend to have high RH and high CS. What values of RH and CS do the new subclasses have? To answer this question, Fig. 8 presents scatterplots of daily-mean values of CS versus RH for the event, nonevent, and the three new classes. Specifically, the points representing days of the failed-event class lie scattered in between the points representing event and nonevent classes (Fig. 8a). Consequently, this class can now be rightly called failed events. In contrast, the points representing the ultrafine-mode peaks days (Fig. 8b) and pollution-related peaks days (Fig. 8c) overlie the points representing the nonevent class. From the seasonal distribution (Fig. 7) and the scatterplots of RH with CS values (Fig. 8b,

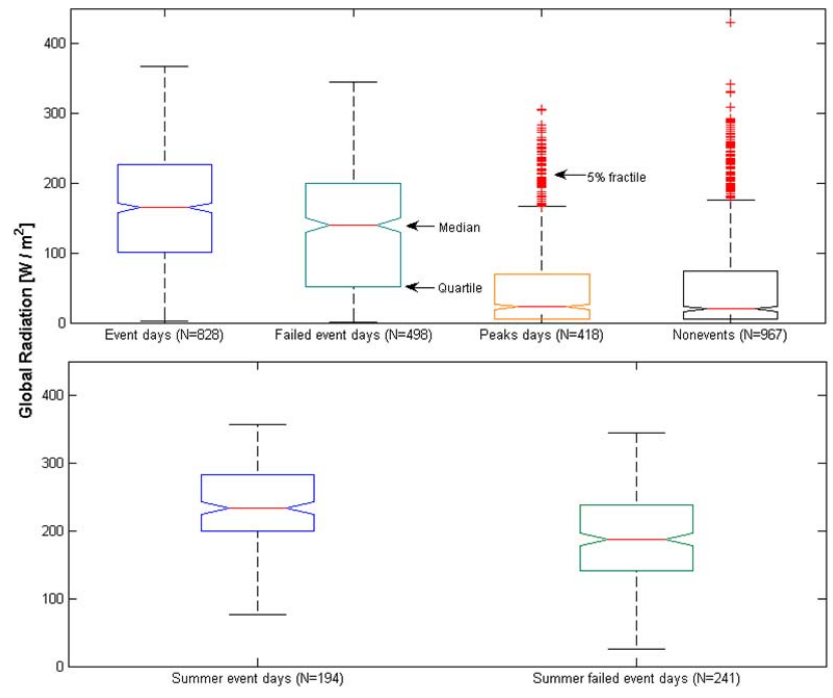

Fig. 9. Upper panel: Global radiation values for event and failedevent classes. Middle panel: global radiation values for nonevent and peaks classes. Lower panel: summer (June-August) radiation values for event and failed-event classes. The median annual values for nonevent and peaks classes fall well below the median of the event and failed-event classes. The distinction between the failedevents classes and the peaks classes is evident.

c), we can now recognize days classified as peaks as nonevent days because they do not exhibit new-particle formation.

Consistent with the above interpretation, event and failedevent groups have higher global radiation values than nonevent and peaks classes (Fig. 9). Summer radiation values show a significant distinction between failed-event and event classes (Fig. 9), providing a possible reason for the less-thanperfect particle-formation conditions found in the summer failed-events. The higher summer radiation values during the event days than the failed-event days suggests a reason for the summer minimum in the frequency of event days, when the failed events reach a maximum. No difference was found when the tail-event and quasi-event subclasses were plotted individually, for either CS versus $\mathrm{RH}$ or for the radiation values.

Rapid growth rates during the summer months could account for the summer minimum in the annual distribution of event days, as the event may be detected in Hyytiälä too late to be classified as such (Mäkelä et al., 2000a, c; Dal Maso et al., 2005). Previous findings (e.g. Kulmala et al., 1998; Mäkelä et al., 2000a; Dal Maso et al., 2005) show a positive relationship between temperature and growth rates, as summer growth rates are more than twice the yearly average growth rate. Thus, why a local minimum exists in the number of new-particle formation events precisely at the time when the conditions are expected to be most favorable is a mystery. 


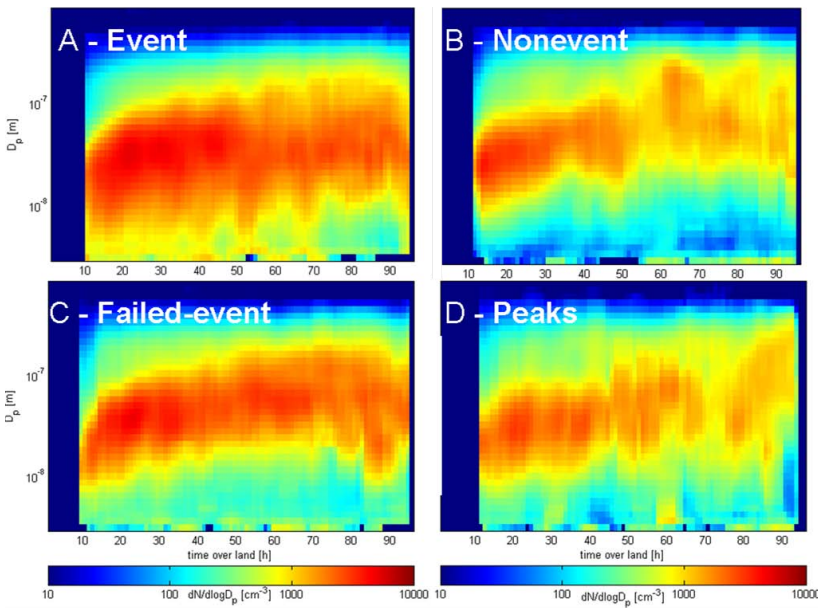

Fig. 10. Mean particle-size distributions plotted as a function of time the air spent over land. The 96-h backward air trajectories ending at Hyytiälä, Finland, were calculated every hour, and were included in this analysis if $90 \%$ of the trajectory ( $86 \mathrm{~h}$ ) occurred within the northwest sector $\left(286^{\circ}-6^{\circ}\right)$, a direction favorable for new-particle formation events at Hyytiälä: (A) event days, (B) nonevent days, (C) failed-event days, and (D) pollution-related and ultrafine-mode peaks classes. The smooth growth of particles in the failed-events class resembles that of the events class (cf. panels A and C), whereas the peaks classes are similar to that of the nonevent class (cf. panels B and D), showing the particle size and number concentration for both nonevent and peaks classes did not increase as fast as for event and failed-events days.

Biogenic vapours emitted from forests are believed to be involved in particle growth while being transported within an air mass (Tunved et al. 2006). Their results show a relationship between the aerosol mass and the time an air mass spends over land, and therefore in direct contact with the biogenic emissions. To investigate the difference in particle concentrations during event, nonevent, and undefined days as a function of time the air spends over land before reaching Hyytiälä, we applied the approach of Tunved et al. (2006), using the HYSPLIT4 model (Draxler and Hess, 1998). The 96-h backward air trajectories ending at Hyytiälä, Finland, were calculated every hour, and were included in this analysis if $90 \%$ of the trajectory $(86 \mathrm{~h})$ occurred within the northwest sector $\left(286^{\circ}-6^{\circ}\right)$, a direction favorable for newparticle formation events at Hyytiälä (Sogacheva et al., 2008, and references within). The event and failed-events classes (Fig. 10a, c) show a continuous maximum in aerosol-particle concentrations starting from the nucleation-mode size range growing to the Aitken-mode size range as the air spends more time over land. The difference occurs because the failedevent class lacks growth of the smallest particles (Fig. 10c), which is one of the main criteria for a day to be classified as an event. By comparison, both the nonevent and peaks classes exhibit little growth from the smallest size-range, and fluctuations in the particle size concentration (Fig. 10b, d).
The new subdivision for the tail-event class can now provide a bin for such events where growth from particles larger than $10 \mathrm{~nm}$ occurs. In addition to the tail-event class, the quasi events, which share characteristics with new particle formation events (e.g. the initial size range of particle growth, hour of occurrence), are potential indicators of atmospheric conditions intermediate between a successful event and a nonevent. Further research of this class can provide more detailed discrimination into which specific parameters may be controlling aerosol-particle formation.

The classification performed in this study is a continuation of the work begun by Dal Maso et al. (2005). In addition to this work, other schemes for classifying particle formation and growth from particle-size distribution data have been presented (e.g. Birmili et al., 2003; Heitzenberg et al., 2005). Also, Hyvönen et al. (2005) is not the only study exploring the ambient conditions leading to particle formation; McMurry et al. (2005), for instance, introduced a parameter based on ambient sulfuric acid and background particle concentrations that can be used to predict the formation and growth of new particles.

\section{Conclusions}

The goal of this article is to further our understanding of atmospheric aerosol-particle nucleation. Previous attempts have led to the classification scheme of Dal Maso et al. (2005), which defines a new particle-formation event or nonevent. Their classification scheme, when applied to the period 1996-2006 in Hyytiälä, Finland, produced about $40 \%$ of the data too ambiguous to be defined as either an event or a nonevent. Consequently, Dal Maso et al. (2005) named these ambiguous days undefined days. In the present study, we refine the Dal Maso et al. (2005) classification by defining the undefined days. Our new classification scheme produced three main subclasses of the previously undefined days: failed events, pollution-related peaks with elevated concentrations of $\mathrm{SO}_{2}$ and $\mathrm{NO}_{\mathrm{x}}$, and ultrafine-mode concentration peaks. These three classes account for $37 \%, 19 \%$, and $34 \%$, respectively, of the 1630 previously undefined days, with $10 \%$ put into an unclassified category.

The results in this article provide new insights into aerosolparticle formation. By joining events with failed events, the difference between summer and winter particle-formationevent frequency is more pronounced, suggesting the contribution of biogenic organics on particle formation and growth (Kulmala et al., 2004b; Tunved et al., 2006). During summer, the high growth rates (Hirsikko et al., 2005; Dal Maso et al., 2005, 2007; Mäkelä et al., 2000a) and high VOC emissions (Allen et al., 2005; Lyubovtseva et al., 2005) have led to speculation that new-particle formation occurs too quickly, away from the observing site, or at a higher altitude in the boundary layer (Kulmala et al., 1998; Mäkelä et al., 2000a) to be detected at the smaller-size ranges (Mäkelä 
et al., 2000a). Were these conditions not present, such days would otherwise be classified as events, likely producing a maximum in the summer. Analysis of our new classification scheme shows that the failed-event class makes up for the summer suppression in the event-days distribution. By combining the number of failed-event days per year (about $15 \%$ of all classifiable days) with the event days (26\%), over $40 \%$ of days during the year either produce new particles or have the potential to produce new particles. More importantly, as a result of our classification scheme, the characteristics that may inhibit new-particle formation on days otherwise favourable may be able to be determined, which will allow a finer discrimination between processes that produce or inhibit the formation of new particles.

Both the pollution-related and ultrafine-mode concentration peak classes have their maximum occurrence in winter, suggesting a very different process is operating during these days. Their abundance during winter and their high values of RH and CS suggest that they are days where particle formation would not otherwise happen. Thus, these two peaks classes are more akin to the nonevent class of Dal Maso et al. (2005).

Acknowledgements. Partial support for Schultz comes from Vaisala Oyj.

Edited by: A. Wiedensohler

\section{References}

Aalto, P., Hämeri, K., Becker, E., Weber. R., Salm, J., Mäkelä, J., Hoel, C., O’Down, C., Karlsson, H., Hansson, H.-C., Väkevä, M., Koponen, I., Buzorius, G., and Kulmala, M.: Physical characterization of aerosol particles during nucleation events, Tellus, 53B, 344-358, 2001.

Allen, G., Remedios, J. J., and Smith, K. M.: Low temperature midinfrared cross-sections for peroxyacetyl nitrate (PAN) vapour, Atmos. Chem. Phys., 5, 3153-3158, 2005,

http://www.atmos-chem-phys.net/5/3153/2005/.

Birmili, W., Berresheim, H., Plass-Dülmer, C., Elste, T., Gilge, S., Wiedensohler, A., and Uhrner, U.: The Hohenpeissenberg aerosol formation experiment (HAFEX): a long-term study including sizeresolved aerosol, $\mathrm{H} 2 \mathrm{SO} 4, \mathrm{OH}$, and monoterpenes measurements, Atmos. Chem. Phys., 3, 361-376, 2003, http://www.atmos-chem-phys.net/3/361/2003/.

Dal Maso, M., Kulmala, M., Riipinen, I., Wagner, R., Hussein, T., Aalto, P. P., and Lehtinen, E. J.: Formation and growth of fresh atmospheric aerosol: eight years of aerosol size distribution data from SMEAR II, Hyytiälä, Finland, Boreal Env. Res., 10, 323336, 2005.

Dal Maso, M., Sogacheva, L., Aalto, P., Riipinen, I., Komppula, M., Tunved, P., Korhonen, L., Suur-uski, V., Hirsikko, A., Kurten. T., Kerminen, V., Lihavainen, H., Viisanen, Y., Hansson, H., and Kulmala, M.: Aerosol size distribution measurements at four Nordic field stations: identification, analysis and trajectories analysis of new particle formation bursts, Tellus ,59B, 350-361, 2007.
Draxler R. R and Hess G. D.: An Overview of the HYSPLIT_4 Modeling System for Trajectories, Dispersion and Deposition. Australian Meteorological Magazine 47, 295-308, 1998.

Doswell III., C. A.: Comments on "Mesoscale convective patterns of the southern high plains.”, B. Am. Meteor. Soc., 72, 389-390, 1991.

Hari, P. and Kulmala, M.: Station for Measuring Ecosystems - Atmosphere Relations (SMEAR II), Boreal Env. Res., 10, 315-322, 2005.

Heintzenberg, J., Wehner, B., and Birmili W.: How to find bananas in the atmospheric aerosol: New approach for analyzing atmospheric nucleation and growth events, Tellus, 59B, 273282, 2007.

Hirsikko, A., Laakso, L., Horrak, U., Aalto, P., Kerminen, V., and Kulmala, M.: Annual and size dependent variations of growth rates and ion concentrations in boreal forest, Boreal Env. Res., 10, 357-369, 2005.

Hyvönen, S., Junninen, H., Laakso, L., Dal Maso, M., Grönholm, T., Bonn, B., Kernonen, P., Aalto, P., Hiltunen, V., Pohja, T., Launiainen, S., Hari, P., Mannila, H., and Kulmala, M.: A look at aerosol formation using data mining techniques, Atmos. Chem. Phys., 5, 3345-3356, 2005, http://www.atmos-chem-phys.net/5/3345/2005/.

Intergovernmental Panel on Climate Change (IPCC), Summary for Policymakers, in: Climate Change 2007: The Physical Science Basis, Cambridge University Press, Cambridge, 2007.

Kulmala, M., Toivonen, A., Mäkelä, J. M., and Laaksonen, A.: Analysis of the growth of nucleation mode particles observed in Boreal forest, Tellus, 50B, 449-462, 1998.

Kulmala, M., Hämeri, K., Aalto, P. P., Mäkelä, J. M., Pirjola, L., Nilsson, E. D., Buzorius, G., Rannik, Ü., Dal Maso, M., Seidl, W., Hoffman, T., Janson, R., Hansson, H.-C., Viisanen, Y., Laaksonen, A., and O'Dowd, C. D.: Overview of the international project on biogenic aerosol formation in the boreal forest (BIOFOR), Tellus, 53B, 324-343, 2001.

Kulmala, M., Vehkamäki, H., Petäjä, T., Dal Maso, M., Lauri, A., Kerminen, V.-M., Birmili, W., and McMurry, P. H.: Formation and growth rates of ultrafine atmospheric particles: A review of observations, J. Aerosol Sci., 35, 143-176, 2004a.

Kulmala, M., Suni, T., Lehtinen, K. E. J., Dal Maso, M., Boy, M., Reissell, A., Rannik, Ü., Aalto, P. P., Keronen, P., Hakola, H., Bäck, J., Hoffmann, T., Vesala, T., and Hari, P.: A new feedback mechanism linking forests, aerosols, and climate, Atmos. Chem. Phys., 4, 557-562, 2004b,

http://www.atmos-chem-phys.net/4/557/2004/.

Kulmala, M., Riipinen, I., Sipilä, M., Manninen, H. E., Petäjä, T., Junninen,H., Dal Maso, M., Mordas, G., Mirme, A., Vana, M., Hirsikko, A., Laakso, L., Harrison, R. M., Hanson, I., Leung, C., Lehtinen, K. E. J., and Kerminen, V.-M.: Toward direct measurement of atmospheric nucleation, Science, 318, 89-92, 2007.

Lyubovtseva, Y. S., Sogacheva, L., Dal Maso, M., Bonn, B., Keronen. P., and Kulmala, M.: Seasonal variations of trace gases, meteorological parameters, and formation of aerosols in boreal forests, Boreal Env. Res., 10, 493-510, 2005.

McMurry, P. H., Fink, M., Sakurai, H., Stolzenburg, M. R., Mauldin, R. L., Smith III., J., Eisele, F., Moore, K., Sjostedt, S., Tanner, D., Huey, L. G., Novak., J. B., Edgerton, E., and Voisin, D.: A criterion for new particle formation in the sulfur-rich Atlanta atmosphere, J. Geophys. Res., 110, D22S02, 
doi:10.1029/2005JD005901, 2005.

Mäkelä, J. M., Koponen, K. I., Aalto, P., and Kulmala, M.: Oneyear data of submicron size modes of tropospheric background aerosol in southern Finland, J. Aerosol Sci., 31(5), 595-611, 2000a.

Mäkelä, J. M., Dal Maso, M., Laaksonen, A., Pirjola, L., Keronon, P., amd Kulmala, M.: Characteristics of three years continuous data on new particle formation events observed at a boreal forest site, Nucleation and Atmopsheric Aerosols 2000: 15th Intl. Conf., Missouri, USA, 6-11 August 2000b.

Mäkelä, J. M., Dal Maso, M., Laaksonen, A., Pirjola, L., Keronon, P., and Kulmala, M.: Characteristics of the atmospheric particle formation events observed at a boreal forest site in southern Finland, Boreal Env. Res., 5, 299-313, 2000c.
Sogacheva, L., Dal Maso, M., Kerminen, V.-M., and Kulmala, M.: Probability of nucleation events and aerosol particle concentration in different air mass types arriving at Hyytiälä, southern Finland, based on back trajectories analysis, Boreal Env. Res., 10, 479-491, 2005.

Sogacheva, L., Saukkonen, L., Nilsson, E. D., Dal Maso, M., Schultz, D. M., de Leeuw, G., and Kulmala, M.: New aerosol particle formation in different synoptic situations at Hyytiälä, southern Finland, Tellus, 60B, 485-494, 2008.

Smart - SMEAR tool: http://www.atm.helsinki.fi/ junninen/, last access: 2007.

Tunved, P., Hansson, H.-C., Kerminen, V.-M., Ström, J., Dal Maso, M., Lihavainen, H., Viisanen, Y., Aalto, P. P., Komppula, M., AND Kulmala, M.: High natural aerosol loading over boreal forests, Science, 312, 261-263, 2006. 